This item was submitted to Loughborough's Research Repository by the author.

Items in Figshare are protected by copyright, with all rights reserved, unless otherwise indicated.

\title{
Sport participation: From policy, through facilities, to users' health, well- being, and social capital
}

PLEASE CITE THE PUBLISHED VERSION

https://doi.org/10.1016/j.smr.2018.01.002

\section{PUBLISHER}

Elsevier (C Sport Management Association of Australia and New Zealand

\section{VERSION}

AM (Accepted Manuscript)

\section{PUBLISHER STATEMENT}

This paper was accepted for publication in the journal Sport Management Review and the definitive published version is available at https://doi.org/10.1016/j.smr.2018.01.002

\section{LICENCE}

CC BY-NC-ND 4.0

\section{REPOSITORY RECORD}

Kumar, Harish, Elisavet Manoli, lan Hodgkinson, and Paul Downward. 2018. "Sport Participation: From Policy, Through Facilities, to Users' Health, Well-being, and Social Capital”. figshare.

https://hdl.handle.net/2134/28207. 


\section{Sport Participation: From Policy, Through Facilities, to Users' Health, Well-Being, and Social Capital}

\section{Authors:}

Harish Kumar

Loughborough University, UK

Dr. Argyro Elisavet Manoli (corresponding author)

School of Sport, Exercise and Health Sciences, Loughborough University,

Loughborough, Leicestershire, LE11 3TU, UK

e.a.manoli@lboro.ac.uk

+44 (0) 1509228453

Dr. Ian R. Hodgkinson

Loughborough University, UK

Prof. Paul Downward

Loughborough University, UK

\section{Acknowledgements}

We acknowledge financial support from the British Academy: Grant number SRG 2015-16. Although dissemination is encouraged by the funder they played no part in the study design; in the collection, analysis and interpretation of data; in the writing of the report; or in the decision to submit the article for publication. 


\section{Sport Participation: From Policy, Through Facilities, to Users' Health, Well-Being, and}

\section{Social Capital}

\section{ABSTRACT}

Sport delivery systems, aimed at facilitating sports participation, represent an interinstitutional, cross-sector collaboration. Researchers focusing on the impact of different levels of sport provision from policy, through facilities, to end users remains limited. The authors address this gap in knowledge through a mixed-methods approach to examine sport participation from the perspective of the whole delivery system. Specifically, focusing on a County Sport Partnership region in the UK, the authors examine sport participation from the policy (macro), facility (meso), and end user (micro) levels. Regional heads responsible for sport development and delivery participated in semi-structured interviews, facility-level managers completed a survey, and end-users across public, private, and outsourced facilities participated in focus groups. Results show a clear divergence between the sport policy goals across the private and public sectors, with significant differences observed between facility types on their social and commercial objectives and their prioritized stakeholder groups. The divergence has little impact on user participation or expression of health, wellbeing, and social capital, offering new evidence on the role of neoliberalism in sport delivery systems.

Keywords: Sport participation, sport delivery, health, wellbeing, social capital, policy. 


\section{Introduction}

The promotion of sports participation is of strategic importance for policy in the United Kingdom (UK) because of its impact on health, wellbeing, personal and social development, and economic development, as outlined in the recent government strategy 'Sporting Future’ (HM Government, 2015). These outcomes are consequently embedded in the policy delivery agency Sport England's most recent strategic initiative 'Towards an Active Nation,' but is resonant of earlier strategies ‘Creating a Sporting Habit for Life’ and investing in 'Places People Play,' in which matching the right facilities to creating sustainable sports participation is an important priority. Such objectives are not unique to the UK and are implicitly enshrined in the European Union (EU) Sports Charter that helps guide panEuropean sports policy. Yet, there is a need to better understand how sport and leisure provision can increase sport participation within local communities. A longstanding current emphasis of policy in Organisation for Economic Co-operation and Development (OECD) countries has spurred a movement away from pure public-sector delivery toward private sector provision and collaboration between the public, private, and voluntary sectors in the management of sport facilities; in other words, there exists a neoliberalisation of the delivery system (Stenling, 2014).

In this context, sport managers must now grapple with the tensions of an interinstitutionalized system and its conflicting demands (Phillips \& Newland, 2014), where the delivery of sport and leisure opportunities differ in their institutional features and logics (Stenling, 2014), despite co-existing in the same delivery system. Sport facilities’ influence on sport participation may, therefore, be varied and not necessarily have a positive impact on sport participation or its associated outcomes for users. This is despite the drive by sport policy to influence the dynamics and strategic direction of delivery systems (Shilbury, O’Boyle, \& Ferkins, 2016; Wicker, Hallmann, \& Breuer, 2013); that is, sport can be a tool to 
solve societal problems (Stenling, 2014). These dynamics illustrate the need to capture the whole delivery system across the macro, meso, and micro levels so that the bigger picture is captured to better inform sport management strategies for mass participation (Rowe, Shilbury, Ferkins, \& Hinckson, 2013). We take a step in this direction.

We structure the paper as follows. First, we establish the theoretical and policy foundations for sport participation research, supporting the relevant outcomes examined: health, wellbeing and social capital. We then offer an overview of the UK sport delivery system and the complexities of this inter-institutional delivery. Next, the key drivers of sports participation and its measurement are presented. Following the presentation of the methods and results, as discuss the findings and highlight implications for sport managers.

\section{Theoretical and policy foundations}

The need to understand the impacts of alternative forms of sports provision on social outcomes reflects the fact that, in general sports provision can be seen as a form of social welfare policy intervention. The precise nature and rationale for intervention does reflect historical ideological and theoretical developments. For example, as Green (2006) argues, the establishment of the the European Sport for All Charter in 1975 reflected the broad welfare state approach to policy that had begun in the 1960s and embraced education, health, and communities. These are interventions in the social domain but they also ran to transport, industry, and finance through state ownership and regulation. As a result, during the 1970s in the UK, there was a large rise in public investment in the provision of sports facilities and, particularly, swimming pools (Gratton \& Taylor, 1991). The election of Margaret Thatcher's government in 1979, however, led to an accelerating trajectory of economics-informed policy moving away from the Keynesian thinking that underpinned state intervention in the 1960s and 1970s, to a monetarist position that involved radically reducing the role of the state in society and embracing free-markets (Hall, 1993). The economic focus of the individual as a 
consumer, and the stress on the market provision of sport has remained since, being captured in both the Blair Labour government’s ‘Game Plan’ strategy (DCMS/Strategy Unit, 2002) and the current strategy developed by the Cameron conservative government's 'Sporting Future’ strategy (HM Government, 2015). Consequently, over this period there has been (a) compulsory outsourcing of public sector leisure services and facilities, (b) the removal of this necessity but with a requirement to show that provision demonstrated 'Best Value' to consumers (Stevens \& Green, 2002), and (c) a rise in the commercial and charitable sector in sports provision (Morgan, 2013). As a result, in the UK and across the EU, there is now the view that government should make provision for its citizens to participate in sports, but government need not be the only provider (European Commission, 2009), and indeed users themselves have a responsibility (Morgan, 2013).

The theoretical basis of the policy developments over the 1980s through to the current period comes from the neoclassical economic approach in which social welfare is represented as the aggregate outcome of individual consumers who, left to their own free choices in markets, allocate their income and time resources to activities that maximise their utility (Downward, Dawson, \& Dejonghe, 2009). The traditional economic measure of value is consequently represented by the value of market transactions, with social welfare represented by the Gross Domestic Product of an economy. More recently, some have argued that an expenditure-based approach to valuing welfare does not capture the full value of activity by ignoring, for example, the quality of life. Following Stiglitz, Sen, and Fitoussi (2010), policy attention has now turned to directly measuring social welfare by asking about individual's utility - expressed as subjective well-being. This is now captured in current policy aspirations (European Commission, 2009; OECD, 2013) and, in the UK context, subjective well-being is an important measure that is required to establish social impact estimates of investment (HM treasury, 2011). Importantly subjective well-being is a complex multidimensional concept, as 
personal well-being, health, and the neighbourhood community are important dimensions that are now being measured to complement the traditional focus on education, employment, and the economy. Consequently, though health has been measured in official statistics for a long time, considerable effort has recently been given to measuring subjective well-being and social capital, for example in Office of National Statistics’ (ONS) Measuring National Wellbeing and Health questionnaire, as well as ONS’ Social Capital Harmonised Question Set. In this research, therefore, we focus on health, subjective well-being, and social capital as outcomes that flow from sports participation.

Currently, in the UK the monitoring and evaluation of these outcomes is informed by large scale surveys, which examine local authority sports participation rates and the number and type of facilities available (e.g., Active People Survey, Active Lives Survey, Active Places Survey). These data do not, however, capture the objectives of organisations seeking to provide sporting opportunities, nor the way in which these opportunities are delivered or managed, which is likely to vary substantially between the public, private, and third sectors. Whilst the Active People Survey only began to investigate well-being in later waves, other data, such as the Taking Part Survey, that has investigated well-being, health, and social capital, lacks any insight into the provision of opportunities. Hence, we address the need to improve sport participation strategies by better understanding the supply-side influences on sport participation and its outcomes (Eime et al, 2015).

It should be noted in this regard the neoclassical economics perspective that underpins the policies and measurement of outcomes predicts that given the opportunity to participate in sport, the form of this arrangement will not matter because individuals will allocate resources to maximise their utility regardless of the legislative arrangements. This flows from the Coase Theorem (Coase, 1960), which has been widely cited in the sports economics and management literature to explain why policies can be ineffective, for example in improving 
competitive balance in sports leagues (Downward et al, 2009). This prediction is important because though there is consensus that sport facilities are fundamental to improving participation and to support improvement or positive change in individuals' and communities' health and well-being (MacIntosh \& Spence, 2012), there is little agreement regarding the nature and form of this association. Morgan (2013), moreover, suggests that the private sector may best be able to achieve this. However, there is a significant gap in understanding the impact of the delivery system on sport participation and subsequent impacts on users' health, well-being, and feelings of connection with their community. Therefore, we address three research questions that span the sport delivery system:

Research Question 1: At the macro level, how do heads of service and regional managers influence the delivery of sport policy objectives across sectors?

Research Question 2: At the meso level, what is the relationship between facility level objectives and the policy objectives outlined at the macro level?

Research Question 3: At the micro level, are users’ health, well-being, and citizenship influenced by the intent of planners (macro level) and the actions implemented by facilities (meso level)?

In addressing these research questions, the contribution of this study to the sport management literature is twofold. First, although recent empirical evidence from Australia suggest that "better provision of sports facilities is generally associated with increased sport participation” (Eime et al, 2017, p. 248), sport management scholars have largely neglected examination of sport facilities as an opportunity to engage the population in physical activity (Rowe et al, 2013). Addressing this neglect, we provide unique insight into the relationship between facility type and sports participation—a relationship which remains poorly understood (Butland et al, 2007). Second, sport delivery is an inter-institutional system characterized by multiple and potentially conflicting logics (Stenling, 2014). We 
consequently examine the role of different cross-sector supply-side actors of sport provision for end users' health, well-being, and social capital, which are key policy targets for the UK and elsewhere (Darcy, Maxwell, Edwards, Onyx, \& Sherker, 2014: Eime et al, 2015), to inform how sport management strategies can deliver on these outcomes.

\section{Literature review}

\subsection{Sport delivery}

Citizens' sport participation in a given society, which could also be referred to as mass participation, can take place either through informal activity or formal governing bodyrelated activity, which is typical for team sports and can also include individual sports such as running, cycling, racquet sports and golf (Downward et al, 2009). Whilst informal and formal activity can be facilitated through open spaces, and many individual and team sports clubs have their own facilities, it is sport and fitness facilities that cater most for mass participation (Downward et al, 2009).

There has been little attention given to the supply-side or the built environment of sport provision on participation (Wicker, et al, 2013) or on local populations' health (AoMRC, 2013). The omission exists despite the fact that the literature on mass participation has emphasized the importance of sport infrastructure (Wicker et al, 2013). Though the availability of sport facilities is identified as important for an individual's participation in sport, there is a suggestion that that all types of sport infrastructure have a positive impact on sport participation in general (Wicker et al, 2013), which is contentious as it assumes homogeneity of the sport infrastructure and impacts. Yet, sport delivery now spans the public, private, and third sectors, and therefore, can best be described as heterogeneous rather than homogenous owing to the neoliberalisation of sport delivery (Stenling, 2014).

Different facility types representative of different sectors are typically associated with different structural features that are expected to impact performance outcomes. For instance, 
in the context of public-private partnerships, private agents are often contended to have a better record of managing projects than pure public sector delivery (van den Hurk \& Verhoest, 2017). However, Kort and Klijin (2011) report that private organizational features do not have a significant impact on outcomes under such arrangements. Nevertheless, sport provision continues to reflect a blend of facility types across the public, private, and third sectors, otherwise referred to as cross-sector collaboration (Shilbury et al, 2016). Coupled with a steep decline in local government spending on sport and leisure has been forecast, there will likely be an even greater propensity of sport delivery outsourcing to private and third sector organizations in the future (Mintel, 2016).

While local governments govern UK sport and leisure facilities, different organizational features of public, non-profit, and private facility types in sport provision exist. Public in-house facilities involve local government directly managing facilities. Since local government is legally obliged to provide core services, such as education, those that are discretionary, such as leisure services, are often given reduced priority. The budgetary process in which this competition occurs may introduce a bias towards cost reduction in areas that the local authority is not legally obliged to provide. In times of austerity, sport and leisure services are starved of investment, with minimal marketing and revenue generation leading to financial pressures. Non-profit facilities are intended to be independent of local government and are generally set up as either Industrial or Provident Societies or as Companies Limited by Guarantee. However, local authorities can exercise significant influence over objectives and operations through a subsidy, in the form of a revenue grant of around $50 \%$ of operating costs or in the form of a management fee income, and secondly, by virtue of its ownership of leisure facilities which are leased typically between 15 and 25 years (Audit Commission, 2006). Private-sector facilities are typically governed and controlled by a parent firm, who are, in turn, either listed firms financed by shareholders or private firms 
with venture capital backing. Private facilities are more likely to be driven by profits, as evidenced by their focus on higher-income groups than their public and non-profit counterparts (Audit Commission, 2006), who are more likely to be focussed on public health, well-being, and community enhancement, given they have their own investment at stake (van den Hurk \& Verhoest, 2017). The competition in the private sector is intense, and at the same time, the consumer need for cheaper sport provision has led to a recent influx in low-cost or budget sport facilities throughout the UK (Trenberth \& Hassan, 2013). A variant of private ownership is where a private agent manages a local government owned facility, otherwise referred to as a Leisure Management Contractor (LMC). Here, local government enters into a performance-based management contract with a private sector operator, who manages the public sector facility with contracts generally lasting anywhere from 5-30 years.

Sport management researchers examining delivery systems typically focus on public or non-profit or private organisations in silo, neglecting the inter-institutional and cross-sector nature of sport systems (Gerke, Babiak, Dickson, \& Desbordes, 2017). Subsequently, how these supply-side nuances impact on sport participation requires much needed investigation.

\subsection{Sports participation: Drivers}

In the current context, we consider sport to include informal activities performed for recreational purposes, such as swimming, running/jogging, cycling, racquet and ball sports, and fitness activities, such as using a fitness suite, yoga, Pilates, and Zumba, among others. Research on sport participation generally, including formal team sports, suggests that men not only participate more in sport than women, but also show higher frequencies of participation, though sport participation in general decreases with age (Downward, Lera-Lopez, \& Rasciute, 2011). There are a variety of antecedents to participation, and these are summarised here. 
Household composition and specifically having active children in the household increases participation but having children who are not active and are under the age of 6 decrease participation, particularly among single parents (Scheerder \& Vos, 2011; Downward et al, 2011). Those who are native to the country of residence (Breuer, Hallmann, \& Wicker, 2011; Ruseski, Humphreys, Hallmann, \& Breuer, 2011) and those who work at the managerial level and above show higher sport participation rates than their counterparts (Stamm \& Lamprecht, 2011; Downward et al, 2011), while people living in urban areas show higher participation levels than those living in rural areas (Garcia, Lera-Lopez, \& Suarez, 2011; Balish, Rainham, \& Blanchard, 2015). However, recent empirical evidence from Australia suggests the opposite relationship (Eime, Harvey, Charity \& Payne, 2016). Watching live sports (Downward et al, 2011), and friends/family’s influence appear to also increase participation levels (Hallmann \& Breuer, 2012; Downward, Hallmann, \& Pawlowski, 2014). Researchers have also shown that lower sport participation levels exist among those with lack of time (Palacios-Ceña et al, 2012), lower income, and lower educational levels (Downward et al, 2011; Thibaut, Vos, \& Scheerder, 2014). In addition, behavioural factors, like drinking alcohol and smoking, are linked with lower sport participation levels (Anokye, Pokhrel, Buxton, \& Fox-Rushby, 2012).

With regard to sport infrastructure, there is positive influence on sport participation behaviour (Wicker et al, 2013). Sport infrastructure characteristics are argued to be crucial not only in the decision to participate in sport, but also for the frequency and duration of sport participation. Identified relevant characteristics include: space available in the facilities, location of facilities, accessibility of sport facilities, and proximity to the sport facility from home/work (Wicker et al, 2013), price related to the use of facility (Anokye, Pokhrel \& FoxRushby, 2014), aesthetic aspects of a sport facility (Wicker, Breuer, \& Pawlowski, 2009; 
Gallardo, Burillo, Garcia-Tascon, \& Salinero, 2009), and types of sports offered in a facility (Hallmann, Wicker, Breuer, \& Schönherr, 2012).

Nevertheless, investigation into the infrastructure determinants of participation has not directly considered the inter-institutional system or cross-sector collaboration that is prevalent in most developed sport delivery systems. Though Wicker et al. (2013) contend that there is general agreement on the theoretical impact of sport infrastructure on sport participation, this assertion is based on sport infrastructure being defined as availability of sport infrastructure and sport facilities. While valid, this ignores critical ownership and management variables within sport delivery, as well as the broader delivery chain influenced by policy and political discourse. The inter-institutional delivery system of sport, we contend, must be acknowledged and accounted for as contextual variation within such systems could have an impact on participation and health, SWB, and social capital as outcomes.

\subsection{Sport participation: Health, well-being, and social capital}

There is consensus that participation carries physical benefits such as preventing coronary heart disease, hypertension, stroke, colon cancer, breast cancer, type 2 diabetes, osteoporosis, and obesity (Allender, Foster, Scarborough, \& Rayner, 2007; Warburton, Nicol, \& Bredin, 2006). Not only does participation carry health benefits, there is vast evidence demonstrating the positive impact of participation on the well-being of individuals (Rasciute \& Downward, 2010; Downward \& Rasciute, 2011), with participants experiencing less depression, less suppressed anger, less cynical distrust, stronger sense of coherence and less perceived stress in comparison to those who exercised less frequently (Hassmén, Koivula, \& Uutela, 2000). Together, then, physically active people are more satisfied with their lives and happier than those who are physically inactive (Stubbe, de Moor, Boomsma, \& de Geus 2007; Ruseski, Humphreys, Hallmann, Wicker, \& Breuer, 2014). 
Trust as a form of social capital is important for an individual's well-being (European Commission, 2009; OECD, 2013). Bonding and bridging capital are both subsumed under social capital (Downward et al, 2014; European Commission, 2009), where bonding capital refers to fostering bonds among a group of individuals who share similar values and characteristics, and bridging capital refers to linking different groups of individuals who share different values and characteristics in a society. Downward, Pawlowski, and Rasciute (2013, p. 4) suggest that "trust, as a form of social capital, can be enhanced by the experience of voluntary association” and social capital, then, can arise from the voluntary association enacted through sport participation, such that, a positive influence of engagement with participation is derived from social experiences (Downward et al, 2013).

Sport participation as a voluntary association is one of the important sources through which social interaction could be achieved that might help to develop trust and civic engagement (Sobel, 2002), thereby improving social capital within a population. The experience of association that generates trust and consequently social capital is viewed as a central general feature of the social capital literature (Delhey \& Newton, 2003). Putnam (2000) has observed that social capital declines due to irregular meeting of acquaintances and reduced association with individuals who may have different values and characteristics. Similarly, empirical findings show that those who engage in physical activity and sports have more friends, meet them more often, and integrate more in social contexts than those who are not physically active contributing to users’ citizenship and social capital (Pawlowski, Downward, \& Rasciute, 2011).

Taken collectively, there is clear evidence of the drivers of participation and its role for health, well-being, and social capital outcomes. There remains, however, insufficient understanding of the role of the supply-side of sport provision for achieving such ends. In particular, there is a distinct lack of evidence connecting the sport delivery system from 
planners/policy makers, through facilities ownership and management, to participants’ behaviour and their health, wellbeing, and social capital. To address these outcomes in this study, the same questions that have been developed by the ONS to inform UK policy are drawn on in order to directly contribute to this policy narrative.

\section{Method}

\subsection{Research setting}

Cross-sector collaborative delivery in UK sport has been organized and overseen by the national network of CSPs, whose role is to promote "sport and physical activity, working closely with local authorities, schools and others” (HM Government, 2015, p.14). CSPs are funded by Sport England who are themselves accountable to the Department for Media, Culture and Sport and can be described as being part of a sport delivery chain that runs from Government, through CSPs, to the end user (Grix \& Phillpots, 2011). Internally, CSPs are governed by an executive board and are supported by a central team of professional staff and “CSPs bring together such diverse actors as NGBs of sport and their clubs, higher and further education representatives, members of the business community, school sport partnerships, local authorities, sport and leisure facilities, primary care trusts and many other sport and non-sporting organizations” (Grix, 2010, p. 458). A CSP, therefore, provides an appropriate setting to capture the sport delivery system and explore the three research questions at the macro, meso, and micro levels.

We focus on a CSP in the Midlands of England. This CSP has a shared commitment to getting more people taking part in sport and physical activity; developing the paid and unpaid workforce; creating a strong voice for sport and physical activity; and building a sport and physical activity infrastructure that is safe, fair and well led. This CSP is a member of the County Sports Partnership Network (CSPN), which is a nationwide network of 44 CSPs committed to working together to provide a cohesive offer to regional and national agencies. 
In any given year, this CSP invests approximately $£ 3.5$ million to support sport and physical activity within the CSP region. Out of the 113 sport and fitness facilities that exists in the selected CSP region, there is 13 in-house public facilities, 85 private facilities, 10 LMC facilities and 5 non-profit facilities.

\subsection{Data generation}

In order to answer the three research questions, we collected data across three levels using a mixed methods approach. At the macro and micro levels, qualitative interviewing was used to capture the sport delivery context and to better understand the phenomenon of sport participation from the users' perspective. We also examined the perceived user outcomes of health, well-being, and social capital. At the macro level, semi-structured interviews were conducted with key individuals responsible for the development of sport in the CSP region. To maintain the representativeness of the inter-institutional, cross-sector collaborative of the CSP region, face-to-face interviews were conducted with five individuals who were selected using purposive sampling and included: 2 private sector consultants, 1 county community development manager, 1 leisure services manager from the District Council, and the CSP Director. Interviews were conducted between April and June 2016. After each interview was completed, it was transcribed, producing 7-9 pages of single spaced text per interview.

At the meso level, in order to capture the varying degrees of importance placed on different facility objectives and stakeholders, single item questions were developed in reference to the Sporting Future document (HM Government, 2015). Different facility features were also examined using single-item measures that were developed with senior officials in the CSP. A pilot of the questionnaire to three facility-level managers and feedback sought from three experts in the sport management field ensured appropriate face and content validity. The questionnaire is included in the online appendices. Single-item measures were adopted since strategic factors are often singular limiting factors (Barnard, 1966), while 
James and Hatten (1995) argue that single item measures are just as robust as multi-item scales in determining the strategic archetype of a firm. Hence, single item measures were deemed appropriate in this research study to capture the strategic objectives, stakeholders influence, and facility features of sport facilities. On the same premise that it is inappropriate to categorise sport organisations as belonging solely to a single strategic type, since sport organisation pursue numerous combinations of service objectives (Hodgkinson \& Hughes, 2014), it was deemed appropriate to adopt Likert-type scales to measure the dependent variables examined from the perception of respondents.

The research team identified 145 sport and fitness facilities in the CSP region that offer informal sports for recreational purposes to the population. In order to maintain the representativeness of this sample, 20 percent of the available facilities were selected to conduct the survey, and due to inter-institutional and cross-sector nature of sport provision in the region, stratified random sampling was employed in which public, private, LMC, and non-profit facilities were selected using SPSS software. This resulted in the selection of 3 public, 17 private, 8 LMC, and 2 non-profit facilities. Prior to survey administration, the questionnaire was piloted with a panel of CSP representatives and academics to ensure appropriate content and face validity. After revising the wording of some items, the survey questionnaire was administered in partnership with the CSP to all 30 facilities of the target population via an online platform. A 100\% response rate was achieved with no missing data to report.

At the micro level, three separate focus groups were organized with users from the sampled public, private, non-profit and LMC facilities, who were selected using purposive criterion sampling (membership to the facility for over six months). The average number of participants per focus group was eight, and interviews were conducted between June and September 2016. Questions followed a semi-structured approach, allowing the participants 
the freedom needed in order for their perceptions, thoughts, and feelings to be conveyed, while being guided by the interviewer to cover the topics under question. Electronic recordings were transcribed, producing 38-40 pages of single spaced text per focus group. A sample list of the qualitative interview questions is found in Appendix A, with the full list given in the online supplementary material.

\subsection{Data analysis}

At the macro and micro levels, once the data collection process was completed and transcribed, manual thematic coding analysis was undertaken and later checked for robustness through intra- and inter-coding. Examining the data carefully and meticulously allowed for the codes identified in the data to be grouped under overarching themes and subthemes, which were then collated in a ‘thematic map' (see Appendices B and C for key themes and illustrative quotes of both macro and micro levels). The data analysis strategy adopted followed the six phases of thematic analysis suggested by Braun and Clarke (2006).

At the meso level, one-way analysis of variance (ANOVA) was used to examine differences in the means for the four facility groups across dimensions that reflect facility objectives, stakeholders, and features. The aim here is to assess group differences across multiple dependent variables in order to better understand the heterogeneities of service delivery at the meso level. When the results were significant, we adopted Tukey post hoc test to identify differences among groups that have significant differences; this is an appropriate method for both equal and unequal sample sizes (Hair, Black, Babin, \& Anderson, 2010). The reporting of one-way ANOVA, with a post-hoc test, in the sport management literature typically comprises the mean, standard deviation, F-ratio, and effect size (e.g., Geurin, \& Burch, 2017; Hodgkinson, Hughes, Hughes, and Glennon, 2017; Park, Mahony, Kim, \& Do Kim, 2015), as adopted here. 


\section{Results}

\subsection{Macro level (RQ1)}

When discussing the current landscape of the industry, all five officials and consultants suggested that the competition is intensifying in the sport and fitness industry, particularly due to the recent influx of cheaper private sector chains. As a result, concerns were expressed, especially from the district council, regarding user retention. While publicsector representatives underlined the need for additional investment, the private-sector consultants suggested that their focus has shifted to differentiation of services and to acquiring market intelligence for a more tailored service offering. All five regional managers agreed that sport provision pertaining to the number of sport and fitness facilities in the CSP area is sufficient. In contrast, their views on sport participation were quite divergent with opposing opinions expressed regarding changes in participation trends. For instance, one private consultant and the CSP Director argued that there has been no change in participation levels recently, the county community development manager and the other private consultant suggested that the numbers are rising, whereas the leisure services manager from the District Council claimed that participation is in fact decreasing.

When the objectives of the different sport organizations were discussed, all interviewees agreed that a clear divide exists between public and private provision. According to the interviewees, the public-sector's focus is on the needs of the population and its subsequent health, well-being and social capital, while the private sector aims at making profit and being financially effective:

So if you look at public providers, they’ve been less worried about cost, less worried about efficiency, with a far greater focus on trying to deliver a greater equality of opportunity, address need, etc .... Private operators ... will be driven by the profit motive ... and they tend to be a million miles away from social need objectives. 
Regardless of their motivations, however, all interviewees argued that the overall financial climate is having an effect on the sport industry. The financial pressures introduced due to the government's austerity measures have created additional challenges for public-sector facilities, which includes non-profit and LMC facilities that are often struggling to find a balance between controlling cost and achieving their objectives. Though public-sector facilities have been charged with national and local government objectives, the public-sector representatives noted that this has not been matched with increased financial assistance to meet these targets. They argued that it is these intensified pressures that will influence future service objectives. In contrast, the private-sector consultants praised the government's policies on increasing sport participation as they viewed this as a means for generating new customers and profit in turn.

The District Council representative and the CSP Director both suggested that while the public-sector seeks a balance between meeting customer needs and offering a consistent set of programmes, they are limited in their ability to adapt to new trends or embrace technological advances that could be of use in their provision; though it was noted that LMCs have a stronger engagement with users particularly in experimenting with their provision. In stark contrast, the private-sector consultants explained how their strategy is not user-led, but rather their approach to provision reflects the belief that they provide the best facilities in the sport delivery system: “I don’t think we are a needs led service, we are incredibly a supplier led service, we focus on basically just marketing and hoping that the marketing approach works in terms of addressing needs”.

\subsection{Meso level (RQ2)}

It would be expected that private sector and public sector sport facilities will differ in their service objectives, with public sector sport facilities pursuing a broader range of service 
objectives relative to private sector organizations (Hodgkinson, 2013). Non-profit organizations, especially, might be expected to pursue objectives that are in the best interests of the community and which serve to cater to those that are recreationally disadvantaged, given the charitable status of many of these types of facilities. The results of the ANOVA analysis in Table 1 suggests that while there appear to be no significant differences in the degree to which disadvantaged groups, specifically, are prioritized in the delivery of sport facilities across private and public contexts, it is observed that public facilities do indeed prioritize community objectives significantly more than the private sector in their service delivery. Moreover, all forms of public sector facilities that include both non-profit and LMCs pursue social objectives significantly more than the private sector. In addition, nonprofit facilities place significantly more strategic emphasis on targeted programming to all market segments than their private sector counterparts, reflective of their social cause. Though LMC facilities belong to the public sector, they are managed by private agents that put their own investment at risk, the implication for sport provision being that LMCs actually pursue commercial objectives significantly more than pure private sector provision. In-house public sector provision is reported to be the most expensive mode of delivery for local government given the government subsidies received, when compared against external nonprofit and LMC organizations (Audit Commission, 2006). This is indirectly observed here, since public facilities are significantly less concerned with the cost efficiency of their provision when compared to all other facility type groups. Though profit and market share might be performance objectives closely associated with private sector organizations, no significant differences are reported between the four groups on these service objectives.

It is typically contended that public-sector service organizations face a wider range of demands from a multitude of stakeholder groups when compared to private sector service organizations (see Osborne, Radnor, \& Nasi, 2013). In the context of sport delivery, we 
observed that sport agencies such as Sport England, national governing bodies of sport, and the CSP have a significantly stronger influence over the decision-making of LMCs compared to private-sector sport facilities. Moreover, local government is a key stakeholder group for public and LMC facilities, carrying significantly more influence over their decision-making compared to private facilities; though differences in the prioritization of government bodies and community/sport clubs are reported to be nonsignificant. With regard to service features, differences in the mean values observed between the four facility groups are reported to be nonsignificant.

\section{...Insert Table 1 About Here...}

\subsection{Micro level (RQ3)}

While all end users argued that they selected the facility predominantly based on the activities offered and its geographical proximity to their home, a disparity was found among the remaining reasons highlighted. LMC and public facility users suggested that their loyalty and sense of belonging to the centre influenced their choice of facility, while private facility users underlined that the additional perks offered, such as aesthetics, parking, cleanliness, and friendliness of staff was the reason behind their choice. All facility users felt that the price strategy of their facility is reasonable, while appreciating that private facilities are expected to function like a profit-driven corporation, as the following quote illustrates:

I'd say the initial fee is quite expensive and a bit of an eye-opener, but with the quality of what you get, as I say, the instruction is available if you need it or if you want it. Opening hours, as I say, you couldn’t pay to sort of go anywhere else at that time, so there’s nowhere else open.

Discontent was expressed by public facility users regarding opening times and space availability, suggesting that often demand substantially exceeds capacity. However, this was not raised by private or LMC facility users, who appeared satisfied with both the opening 
times and the space provided. It is worth mentioning that when asked about areas for improvement, all facility users argued that there is need for improvement with regards to facility cleanliness and, particularly for public facility users, upgrading of equipment.

In terms of their subjective health, well-being and social capital, identical themes emerged from all users who emphasized the socializing and networking opportunities that using a sport facility provides, as the following quotes demonstrate:

In the gym you see friendships, you see bonds, you see people like really dig deep for someone else. (public facility).

Get talking to people, networking with people and just being healthy and getting that. (LMC facility).

It is a family environment. I'd say it's important and it's sort of gone beyond keeping yourself fit that becomes expected for having the gym. In partly the social side and your family environment it's somewhere to meet and go on from there onwards. (private facility).

Improved networking and meeting new people was mentioned by all users who emphasized that the social atmosphere is a key motivating factor for them to participate. As the users suggested, the social bonds created through participating at a facility extend beyond the training hours and into their social life, enhancing wellbeing and social capital.

The physical and psychological benefits cited by all users included their improved health and fitness, as well as their increased energy, paired with an enhanced sense of confidence, optimism and overall well-being, as the following quotes illustrate: 
Confidence for feeling physically fitter and feeling stronger. That gives me a kind of an inner sense of strength, plus a bit of vanity as well. (private facility).

Being able to do the class, survive it and stick with it and see my fitness level change has really impacted on my sense of wellbeing and kind of like how I feel about myself ultimately. I am alive, do stuff! (Non-profit facility).

A lot of us find that once you go to the gym maybe once or twice, you start to feel a lot better about yourself, rather than being cooped up in the house. Not only from a physiological point of view, but also from a mental perspective, it made me feel better. (public facility).

The end users of all facilities suggested that the effect sport participation has on their health and physical condition, such as increased fitness levels and weight loss, has benefited them psychologically while increasing their sense of well-being. The overall effects of their participation extend beyond the individual benefits they received, according to the users, who argued that sport participation has even allowed them to improve their relationship with their family. Based on the identical themes that emerged from all users, it appears that the perceived health, well-being and social capital obtained is not influenced by the type of facility used.

\section{Discussion}

In response to the first research question, the findings illustrate that at the macro level, heads of service and regional managers are influencing facility-level provision, though there is a contrast in the delivery of sport policy objectives across sectors. For instance, public 
officials are concerned with the health, well-being, and social capital in their constituency, while those responsible for overseeing private sector provision are driven by profit. Current UK sport policy emphasizes sport for social good, a focus on social outcomes, and a need to understand the differing requirements of different groups (HM Government, 2015), and this is consistent with the views of those public officials interviewed, and manifest in the objectives of public sector facilities. Specifically, in answer of the second research question, the motivations for sport delivery at the macro level are reflected in facility objectives at the meso level across the different facility types. For example, public sector facilities are significantly more likely to pursue community and social objectives, as well as targeted programming, when compared with their private sector counterparts. While at the macro level, there appeared to be a strong belief in service differentiation among private consultants with the aim to enhance their revenue stream, akin to Coalter's (1995) observation of entrepreneurialism versus welfarism, this was not significantly reflected in the between groups differences at the meso level, contrary to expectation.

MacIntosh and Spence (2012) contend that values guide managers' behaviour and preferences for outcomes, and the findings reported here largely support this suggestion, given the reported differences in opinions and objectives in cross-sector delivery. However, though a public facility might value social inclusion and well-being and indeed prioritize these outcomes, this does not mean that the achievement of these outcomes will follow. One explanation here may be that there is weak understanding of user's perceived values (MacIntosh \& Spence, 2012), such that users are not concerned about equality of programming or access, but rather are more likely to participate when facilities are characterized by flexible opening times, space, availability of equipment, cleanliness, and quality equipment. Thus, physical evidence of provision (e.g., quality of equipment) and the 
value proposition appear to matter most to users (Hodgkinson, 2013) regardless of the type of facility or the objectives of those facilities.

Neoliberalism has spurred the outsourcing of sport facilities to external private and non-profit agents on the premise that external agents are better equipped to provide sport and leisure opportunities (e.g., van den Hurk \& Verhoest, 2017). However, as previously discussed, an important tenet of neoclassical economics is that often the form of organisation of resource allocation is not as important as the possibility that individuals can adapt their behaviour to best suit their judgement of their welfare. Based on the findings, consequently, it is this latter proposition in the neoliberal approach that appears to receive support. Specifically, there is no apparent difference in the participation and outcomes of users between public and private facilities. What we see here, then, is a clear divergence in terms of the institutional logics espoused between public and private facilities (Stenling, 2014), but also variation in the logics held between different public sector facilities e.g., public and LMC facilities. This points to the notion that while neoliberalism has led to the deregulation and privatization of sport delivery, we should not claim that the actions of private or public actors involved in the management of facilities should be interpreted as being homogenous (i.e., differences exist in their objectives illustrating the autonomous nature of sport delivery). Thus, while Shilbury et al. (2016) report that the values and strategic priorities are common to all member associations’ plans of national sport organizations’ in an Australian sport context, such cohesiveness across the UK sport delivery system is absent; but, does this actually matter for users’ participation and their health, well-being, and social capital?

In answer to the third research question, this divide in objectives is not observed at the micro level, as the end users' views on their subjective health, well-being, and social outcomes are identical across different types of facilities. In other words, the anticipated antithesis between public sport provision that aims primarily for social outcomes versus 
private for-profit provision that might fall short in delivering social goods was in fact not found. On the contrary, the views expressed seem to suggest that the type of facility or the facility objectives pursued have no direct effect on their perceived health, well-being, or social capital. It could, therefore, be argued that facility type and the specific objectives pursued might actually not materialize in expected outcomes (i.e., a socially-oriented nonprofit provider does not necessarily achieve social outcomes beyond those realized by private agents; see Hodgkinson \& Hughes, 2012). Rather, participation is driven by the opportunity for social encounters and a social network (Yoshida, 2017), but this appears contingent on users’ desire to co-create social capital.

Clearly, the objectives pursued across the four facility groups are influenced by macro level forces, but there were no significant differences reported in the respective service features between facility types. From the users' perspective, then, this would suggest that it is actually quite difficult to discern the differences between a private sector facility versus a public sector facility. More importantly, in the context of delivering upon sport policy goals, if facility features do not differ then it is difficult to determine why public sector facilities would be any more effective than the private sector in delivering health, wellbeing, and social capital outcomes; despite the objectives being pursued. While organisational objectives differ on the ground, this does not appear to influence the service experience for users, their participation, or health, subjective well-being, and social capital outcomes.

\section{Implications, future directions, and conclusions}

The findings of this research raise new questions about the impact of neoliberalism in sport delivery, and specifically, the role of the private sector in delivering outcomes such as health, well-being, and social capital: outcomes that have long been deemed to be only the preserve of public sector delivery. Conversely, it could be argued that private agents are just as well positioned as public sector delivery to meet health, wellbeing and social targets. An 
alternate conclusion, however, is that neoliberalism has not produced a more effective sport delivery system, as if it had, we would expect external agents to not simply have parity in the outcomes realized, but to actually contribute more than in-house public sector delivery to users' health, subjective well-being, and social capital. This supports the related conclusions of Kort and Klijin (2011) and Hodgkinson et al. (2017) that private agents should not be assumed to be the best form of delivery, since we do not see any clear differences on the impact on participation between different facility types.

These conclusions are tempered by the fact that user perceptions and facility type characteristics may vary outside of the research setting examined here. In addition, the research design adopted is cross-sectional, and we must caution against inferring causality between types of organizations and their objectives, and the outcomes for end users. The relationships examined across levels are complex. For instance, social capital appears to be achieved equally well across the delivery system and between facility types, and it is users themselves that contribute to the development of social capital in communities (Darcy et al, 2014), but only when there is opportunity to do so through social encounters, as uncovered here. Rather than organizational structures, values, and practices facilitating social capital, then, it appears here to be facilitated by the actual act of participation itself rather than any specific characteristics of sport delivery (cf. Forde, Lee, Mills, \& Frisby, 2015). A quantitative investigation exploring causal links between facility ownership and configuration of services on sport and physical activity behaviour and outcomes appears to be a fruitful avenue for future research to expand on the emerging findings presented here. A second avenue for future research is to move beyond the notion of sport delivery as a value chain where linearity of delivery is implicit. Future qualitative research investigation should explore users' influence on the sport delivery system; from user, through facility, to policy. 


\section{References}

Allender, S., Foster, C., Scarborough, P., \& Rayner, M. (2007). The burden of physical activity-related ill health in the UK. Journal of Epidemiology and Community Health, 61(4), 344-348.

Anokye, N. K., Pokhrel, S., Buxton, M., \& Fox-Rushby, J. (2012). Physical activity in England: Who is meeting the recommended level of participation through sports and exercise? European Journal of Public Health, 23(3), 458-464.

Anokye, N. K., Pokhrel, S., \& Fox-Rushby, J. (2014). Economic analysis of participation in physical activity in England: Implications for health policy. International Journal of Behavioural Nutrition and Physical Activity, 11(117), 1-12.

AoMRC. (2013). Measuring up: The medical profession's prescription for the nation's obesity crisis. London: Academy of Medical Royal Colleges.

Audit Commission. (2006). Public sports and recreation services: Making them fit for the future. London: Audit Commission for local authorities and the National Health Service in England

Balish, S. M., Rainham, D., \& Blanchard, C. (2015). Community size and sport participation across 22 countries. Scandinavian Journal of Medicine \& Science in Sports, 25(6), 576-581.

Barnard, C. L. (1966). The Functions of the Executive. Harvard University Press, Cambridge, MA.

Braun, V. and Clarke, V. (2006). Using thematic analysis in psychology. Qualitative Research in Psychology, 3(2). pp. 77-101.

Breuer, C., Hallmann, K., \& Wicker, P. (2011). Determinants of sport participation in different sports. Managing Leisure, 16(4), 269-286. 
Butland, B., Jebb, S., Kopelman, P., McPherson, K., Thomas, S., Mardell, J., \& Parry, V. (2007). Foresight. Tackling obesities: Future choices. Project report. London: Government Office for Science.

Coalter, F. (1995). Compulsory competitive tendering for sport and leisure management: A lost opportunity. Managing Leisure, 1(1), 3-15.

Coase, R. H. (1960). The Problem of Social Cost. Journal of Law and Economics, 3, 1-44.

Darcy, S., Maxwell, H., Edwards, M., Onyx, J., \& Sherker, S. (2014). More than a sport and volunteer organisation: Investigating social capital development in a sporting organisation. Sport Management Review, 17(4), 395-406.

Delhey, J., \& Newton, K. (2003). Who Trusts? The Origins of Social Trust in Seven Societies. European Societies, 5(2), 93-137.

Department for Digital, Culture, Media and Sports. (2002). Game Plan: A strategy for delivering Government’s sport and physical activity objectives. Retrieved from: http://www.gamesmonitor.org.uk/files/game_plan_report.pdf

Downward, P., Dawson, A., \& Dejonghe, T. (2009). The Economics of Sports: Theory, Evidence and Policy. Oxford: Butterworth-Heinemann.

Downward, P., Hallmann, K., \& Pawlowski, T. (2014). Assessing parental impact on the sports participation of children: A socio-economic analysis of the UK. European Journal of Sport Science, 14(1), 84-90.

Downward, P., Lera-Lopez, F., \& Rasciute, S. (2011). The Zero-Inflated ordered probit approach to modelling sports participation. Economic Modelling, 28(6), 2469-2477

Downward, P., Pawlowski, T., \& Rasciute, S. (2013). Does associational behavior raise social capital? A cross-country analysis of trust. Eastern Economic Journal, 40(2), 150-165. 
Downward, P., \& Rasciute, S. (2011). Does sport make you happy? An analysis of the wellbeing derived from sports participation. International Review of Applied Economics, 25(3), 331-348.

Eime, R. M., Harvey, J., Charity, \& Payne, W. R. (2016). Population levels of sport participation: Implications for sport policy. BMC Public Health, 16, https://doi.org/10.1186/s12889-016-3463-5

Eime, R. M., Harvey, J., Charity, M. J., Casey, M., Westerbeek, H., \& Payne, W. R. (2017). The relationship of sport participation to provision of sport facilities and socioeconomic status: A geographical analysis. Australian and New Zealand Journal of Public Health, 41(3), 248-255.

Eime, R. M., Sawyer, N., Harvey, J. T., Casey, M. M., Westerbeek, H., \& Payne, W. R. (2015). Integrating public health and sport management: Sport participation trends 2001-2010. Sport Management Review, 18(2), 207-217.

European Commission (2009). Report by the Commission on the Measurement of Economic Performance and Social Progress. Retrieved from http://ec.europa.eu/eurostat/documents/118025/118123/Fitoussi+Commission+report

Forde, S. D., Lee, D. S., Mills, C., \& Frisby, W. (2015). Moving towards social inclusion: Manager and staff perspectives on an award winning community sport and recreation program for immigrants. Sport Management Review, 18(1), 126-138.

Gallardo, L., Burillo, P., Garcia-Tascon, M. \& Salinero, J. J. (2009). The Ranking of the Regions With Regard to Their Sports Facilities to Improve Their Planning in Sport: The Case of Spain. Social Indicators Research, 94, 297-317.

Garcia, J., Lera-Lopez, F., \& Suarez, M. J. (2011). Estimation of a structural model of the determinants of the time spent on physical activity and sport: Evidence for Spain. Journal of Sports Economics, 12(5), 515-537 
Gerke, A., Babiak, K., Dickson, G., \& Desbordes, M. (2017). Developmental processes and motivations for linkages in cross-sectoral sport clusters. Sport Management Review, DOI.org/10.1016/j.smr.2017.05.005.

Geurin, A. N., \& Burch, L. M. (2017). User-generated branding via social media: An examination of six running brands. Sport Management Review, 20(3), 273-284.

Gratton, C., \& Taylor, P. (1991). Government and the economics of sport. Harlow, UK: Longman Group UK Ltd.

Green, M. (2006). From 'Sport for All' to Not About 'Sport' at All?: Interrogating Sport Policy Interventions in the United Kingdom. European Sport Management Quarterly, 6(3), 217-238.

Grix, J. (2010). Introducing 'hard’ interpretivism and 'Q’methodology: Notes from a project on ‘county sport partnerships and governance’. Leisure Studies, 29(4), 457-467.

Grix, J., \& Phillpots, L. (2011). Revisiting the 'governance narrative' 'asymmetrical network governance' and the deviant case of the sports policy sector. Public Policy and Administration, 26(1), 3-19.

Hair, J. F., Black, W. C., Babin, B. J. \& Anderson, R.E. (2010). Multivariate Data Analysis ( $7^{\text {th }}$ edition). New York: Pearson.

Hall, R. (1993). A framework linking intangible resources and capabilities to sustainable competitive advantage. Strategic Management Journal, 14(8), 607-18.

Hallmann, K., \& Breuer, C. (2012). The influence of socio-demographic indicators economic determinants and social recognition on sport participation in Germany. European Journal of Sport Science, 14(S1), S324-S331

Hallmann, K., Wicker, P., Breuer, C., \& Schönherr, L. (2012). Understanding the importance of sport infrastructure for participation in different sports-findings from multi-level modelling. European Sport Management Quarterly, 12(5), 525-544. 
Hassmen, P., Koivula, N., \& Uutela, A. (2000). Physical Exercise and Psychological WellBeing: A Population Study in Finland. Preventive Medicine, 30(1), 17-25.

Her Majesty’s Treasury (2011). Valuation Techniques for Social Cost-Benefit Analysis: Stated Preference, Revealed Preference and Subjective Well-Being Approaches. A Discussion of the Current Issues. Retrieved from https://www.gov.uk/government/uploads/system/uploads/attachment_data/file/209107 /greenbook_valuationtechniques.pdf

Her Majesty’s Government. (2015). Sporting future: A new strategy for an active nation. London: Cabinet Office.

Hodgkinson, I. R. (2013). Are generic strategies 'fit for purpose 'in a public service context?. Public Policy and Administration, 28(1), 90-111.

Hodgkinson, I. R, \& Hughes, P. (2012). A level playing field: Social inclusion in public leisure. International Journal of Public Sector Management, 25(1), 48-63.

Hodgkinson, I. R., \& Hughes, P. (2014). Strategy content and public service provider performance in the UK: An alternative approach. Public Administration, 92(3), 707726.

Hodgkinson, I. R., Hughes, P., Hughes, M., \& Glennon, R. (2017). Does ownership matter for service delivery value? An examination of citizens' service satisfaction. Public Management Review, DOI: 10.1080/14719037.2016.1272711.

James, W. L., \& Hatten, K. J. (1995). Further evidence on the validity of the self-typing paragraph approach: Miles and Snow strategic archetypes in banking. Strategic Management Journal, 16(2), 161-168.

Kort, M., \& Klijn, E. H. (2011). Public-private partnerships in urban regeneration projects: Organizational form or managerial capacity? Public Administration Review, 71(4), 618-626. 
Morgan, H. (2013). Sport volunteering, active citizenship and social capital enhancement: What role in the 'Big Society'? International Journal of Sport Policy and Politics, 5(3), 381-395.

MacIntosh, E., \& Spence, K. (2012). An exploration of stakeholder values: In search of common ground within an international sport and development initiative. Sport Management Review, 15(4), 404-415.

Mintel. (2016). Leisure Centres and Swimming Pools - UK. London: Mintel Group.

Organization for Economic Cooperation and Development. (2013). How’s Life? 2013:

Measuring Well-being. Retrieved from http://www.oecd.org/std/3013071e.pdf

Osborne, S.P., Radnor, Z., \& Nasi, G. (2013). A new theory for public service management? Toward a (public) service-dominant approach. The American Review of Public Administration, 43(2), 135-158.

Palacios-Ceña, D., Fernandez-de-Las-Peñas, C., Hernández-Barrera, V., Jiménez-Garcia, R., Alonso-Blanco, C., \& Carrasco-Garrido, P. (2012). Sports participation increased in Spain: A population-based time trend study of 21381 adults in the years 2000, 2005 and 2010. British Journal of Sports Medicine, 46(16), 1137-1139.

Park, S. H., Mahony, D. F., Kim, Y., \& Do Kim, Y. (2015). Curiosity generating advertisements and their impact on sport consumer behavior. Sport Management Review, 18(3), 359-369.

Pawlowski, T., Downward, P., \& Rasciute, S. (2011). Subjective well-being in European countries - on the age-specific impact of physical activity. European Review of Aging and Physical Activity, 8(2), 93-102

Phillips, P., \& Newland, B. (2014). Emergent models of sport development and delivery: The case of triathlon in Australia and the US. Sport Management Review, 17(2), 107-120. 
Putnam, R. D. (2000). Bowling Alone: The Collapse and Revival of the American Community. New York: Simon and Schuster.

Rasciute, S., \& Downward, P. (2010). Health or happiness? What is the impact of physical activity on the individual? KYKLOS, 63(2), 256-270

Rowe, K., Shilbury, D., Ferkins, L., \& Hinckson, E. (2013). Sport development and physical activity promotion: An integrated model to enhance collaboration and understanding. Sport Management Review, 16(3), 364-377.

Ruseski, J. E., Humphreys, B. R., Hallmann, K., \& Breuer, C. (2011). Family structure, time constraints, and sport participation. European Review of Aging and Physical Activity, 8(2), 57-66.

Ruseski, J. E., Humphreys, B. R., Hallmann, K., Wicker, P. \& Breuer, C. (2014). Sport participation and subjective well-being: Instrumental variable results from German survey data. J Phys Act Health, 11, 396-403.

Scheerder, J., \& Vos, S. (2011). Social stratification in adults’ sports participation from a time-trend perspective results from a 40-year household study. European Journal for Sport and Society, 8(1/2), 31-44.

Shilbury, D., O’Boyle, I., \& Ferkins, L. (2016). Towards a research agenda in collaborative sport governance. Sport Management Review, 19(5), 479-491.

Sobel, J. (2002). Can We Trust Social Capital? Journal of Economic Literature, 40(1), 139154.

Stamm, H., \& Lamprecht, M. (2011). Swiss sports participation in an international perspective. European Journal for Sport and Society, 8(1/2), 15-29.

Stenling, C. (2014). The emergence of a new logic? The theorizing of a new practice in the highly institutionalized context of Swedish voluntary sport. Sport Management Review, 17(4), 507-519. 
Stevens, D., \& Green, P. (2002). Explaining continuity and change in the transition from Compulsory Competitive Tendering to Best Value for sport and recreation management. Managing Leisure, 7(2), 124.138.

Stiglitz, J. E., Sen, A., \& Fitoussi, J. P. (2010). Mismeasuring our lives: Why GDP Doesn’t add up. New York: The New Press.

Stubbe, J. H., de Moor, M. H. M., Boomsma, D. I., \& de Geus, E. J. C. (2007). The association between exercise participation and well-being: A co-twin study. Preventive Medicine, 44(2), 148-152

Thibaut, E., Vos, S., \& Scheerder, J. (2014). Hurdles for sports consumption? The determining factors of household sports expenditures. Sport Management Review, 17(4), 444-454.

Trenberth, L., \& Hassan, D. (2013). Managing the Business of Sport: An Introduction. Oxon, US: Routledge.

van den Hurk, M., \& Verhoest, K. (2017). On the fast track? Using standard contracts in public-private partnerships for sports facilities: A case study. Sport Management Review, 20(2), 226-239.

Warburton, D., Nicol, C., \& Bredin, S. (2006). Health benefits of physical activity: The evidence. Canadian Medical Association Journal, 174(6), 801-809.

Wicker, P., Breuer, C. \& Pawlowski, T. (2009). Promoting sport for all age-specific target groups: The impact of sport infrastructure. European Sport Management Quarterly, 9(2), 103-118.

Wicker, P., Hallmann, K., \& Breuer, C. (2013). Analyzing the impact of sport infrastructure on sport participation using geo-coded data: Evidence from multi-level models. Sport Management Review, 16(1), 54-67. 
Yoshida, M. (2017). Consumer experience quality: A review and extension of the sport management literature. Sport Management Review, DOI.org/10.1016/j.smr.2017.01.002. 